\title{
Preferences of dentists and endodontists, in Saudi Arabia, on management of necrotic pulp with acute apical abscess
}

Ahmad A. Madarati ${ }^{1,2}$ (D)

\begin{abstract}
Background: This study aimed at investigating dental clinicians' preferences on management of necrotic pulp with acute apical abscess (NPAAA) cases.

Methods: Following an ethical approval and two pilot studies, an electronic survey was emailed to 400 general dental practitioners (GDPs) and 56 endodontists. The email explained the study's methods and assured that participants' identities and information given would remain anonymous and confidential. A reminder email was sent after eight weeks. Responses were collected and data were analyzed using the Chi-square test at $p=0.05$.

Results: The majority of respondents (86.3\%) would deal with NPAAA cases "differently" from vital-pulp ones $(p<0.001)$. More endodontists (40\%) used two or three irrgants than GDPs (29.5\%). Whilst the highest proportion of endodontists (29.7\%) rarely prescribed antibiotics, the highest proportion of GDPs $(26 \%)$ generally did so $(p<0.001)$. Whilst the highest proportion of GDPs (26.9\%) over-instrumented the largest canal in the first visit, most endodontists (56.8\%) performed complete cleaning \& shaping (C\&S) $(p<0.001)$. In cases of non-stopped exudates, whilst the highest proportions of endodontists would either let the patient wait till the exudates significantly reduce then continue their intended approach (40.5\%) or insert ICMs and temporize the tooth (40.5\%), the highest proportion of GDPs (30.8\%) would insert only dry cotton pellet without temporizing the tooth $(p=0.002)$. Of those who would leave the tooth open if non-stopped exudates presents in the first visit, the majority (81.9\%) would temporize the tooth if little exudates present after C\&S $(p<0.001)$.

Conclusions: Clinicians, especially GDPs, opted to treat teeth involved in NPAAA differently from those with vital-pulp, such as: were using different ICMs and irrigants, C\&S to different apical size preparation. GDPs should improve their practice by implementing multi-irrigants protocol while C\&S, limit prescribing antibiotics, perform complete debridement of the root canal system and not to leave the tooth open between visits. Clinicians, especially GDPs, relied on their own experiences in managing NPAA cases which necessitates scientific-based guidelines.
\end{abstract}

Keywords: Acute, Apical, Abscess, Endodontics, Emergencies, Pus, Questionnaire, Necrotic, Survey

\section{Background}

The main objectives of root canal treatments are: a- to remove the infection from the root canal system (elimination of microbes), b- to perfectly seal the root canal system to prevent re-infection, and c- to promote healing of the periapical tissues. Accomplishment of these objectives, however, in some cases is challenging. Diagnosis

Correspondence: amadarati@taibahu.edu.sa; ahmad.madarati@hotmail.co.uk ${ }^{1}$ Restorative Dental Sciences Department, College of Dentistry, Taibah University, P.O Box 2898, Madina 43353, Saudi Arabia

${ }^{2}$ Faculty of Dentistry, Aleppo University, Aleppo, Syria and management of necrotic dental pulp cases that are associated with apical pathosis possess difficulties. Misdiagnosis or improper treatment procedures, due to lack of knowledge or insufficient clinical skills, may result in serious consequences for the patient. Clinicians must identify the etiology and mechanism of the periapical tissues' pathosis and manage the case properly by providing the appropriate treatment measures. The role of bacteria and their toxic by-products in pathosis of the dental pulp and periradicular tissues is well established [1]. Therefore, after determining the corrected working length, complete

(c) The Author(s). 2018 Open Access This article is distributed under the terms of the Creative Commons Attribution 4.0 International License (http://creativecommons.org/licenses/by/4.0/), which permits unrestricted use, distribution, and reproduction in any medium, provided you give appropriate credit to the original author(s) and the source, provide a link to the Creative Commons license, and indicate if changes were made. The Creative Commons Public Domain Dedication waiver (http://creativecommons.org/publicdomain/zero/1.0/) applies to the data made available in this article, unless otherwise stated. 
canal debridement, with / without obturation, is the treatment of choice [2]. However, if the time is limited in the first visit, partial debridement at the estimated working length can be a practical and accepted therapeutic procedure [2]. It is suggested that the root canal system of the offended tooth is dried and then filled with calcium hydroxide and the coronal access cavity is sealed with a temporary filling [2]. While different inter-appointment medications can be recommended, there is a general belief that such a tooth should not be generally left open till next visit [2]. Moreover, in acute apical abscess, the use of systemic antibiotics has not been proved beneficial if the infection is localized [3] However, unfortunately general dental practitioners (GDPs) seem not to follow these recommended procedures. For example, in cases of pulp necrosis associated with periapical pathosis (especially acute apical abscess), leaving the tooth open has been a controversial, but disappointedly is a common practice, to some extent [4]. Walton and Keiser stated that placing a cotton pellet lightly dampened with an intracanal chemical medication in the pulp chamber before placing temporary filling is a useless procedure [2], though it is well adopted by GDPs. These are some of other procedures that GDPs may still follow without scientific evidence. Unfortunately, there has been lack of information regarding clinicians' practices and preferences in this respect. Two previous surveys, conducted in the United States, showed how clinicians change their decision over period of time $(5-7]$. To this end, there is a need to explore management aspects and practitioners' preferences and practices when dealing with cases of necrotic pulp associated with acute apical abscess (NPAAA). In particular, to date there are no reports on the real-life practice of GDPs and endodontists, neither in Saudi Arabia nor in any other country, when a case of NPAAA is encountered.

Therefore, the aim of this questionnaire study was to investigate the preferences, practices and experience of GDPs and endodontists in the Western Province, Saudi Arabia towards management of NPAAA cases. The survey mainly aimed to answer the following questions:

$\square$ Would be there any significant difference between clinicians (GDPs and endodontists) who used to leave the tooth with NPAAA open after the first visit and those clinicians who do not?

$\square$ Would be any significant difference between GDPs and endodontists regarding procedures adopted in the first visit of dealing with a tooth associated with NPAAA?

Therefore, the following two null hypotheses were tested:

$\square$ H0 (1): There would be no significant differences between clinicians (GDPs and endodontists) who would leave a tooth associated with NPAAA open in the first visit and those who wouldn't.

$\square$ H0 (2): There would be no significant difference between GDPs and endodontists regarding some procedures followed in the first visit when dealing with a tooth associated with NPAAA open in the first visit.

\section{Methods}

This Internet-based questionnaire study was ethically approved by the Research Ethics Committee at Taibah University College of Dentistry (Saudi Arabia) without the need for participants' consent form. The study was accomplished in accordance to the World Medical Association's Helsinki Declaration between March and August 2016. A first pilot survey study was conducted on the academic staff at College of Dentistry, Taibah University to ensure that the questions were easily understood without personal interpretation. An initial questionnaire comprised both close-ended and partially close-ended questions in two main categories:

- Demographics (three non-numbered questions)

- Pattern of practice and experience of management of cases associated with NPAAA (14 main questions)

A second pilot survey was performed on a group of GDPs and endodontists to facilitate the sample size calculation. The latter was performed taking into consideration the following factors:

90\% power to detect the difference between groups' proportions

$\square$ The expected (minimum desired) response rate (40-60\%)

$\square$ The populations of the study target (number of GDPs and all endodontists in the Western Province, SA)

$\square$ Level of statistical significant difference (0.05)

It was decided that the survey would be sent to 400 GDPs and all endodontist registered in the Western Province, Saudi Arabia (56). The 400 GDPs were selected randomly using the systematic sampling method. The final questionnaire (Additional file 1) was constructed electronically using the Google Drive sheet. The electronic survey was emailed to the selected sample size (400 GDPs and 56 endodontists). The email explained the aims and methods of the study and assured that participants' identities would remain anonymous and all information given would remain confidential and would be used for the purpose of the research only. A further email was sent to all candidates after eight weeks to remind non-respondents to participate in the survey. Responses were collected using the Google Drive Excel document. Data were entered into SPSS 19 for Windows software (SPSS Inc., Chicago, IL, 
USA) and they were analyzed using the Chi-square and Linear-by-Linear Association tests at $p=0.05$. Statistical tests were performed to compare mainly among the proportions of each question responses and to compare between GDPs and endodontists regarding these responses.

\section{Results}

\section{Classification of Respondents \& Study's response rate}

Of the 456 who were approached, 234 responded to this study as follows: 189 (80.6\%) were GDPs, 32 (13.7\%) endodontists, $6(2.6 \%)$ postgraduate students or residents in endodontic specialty programmes, and 7 (3\%) others.

Eighteen respondents (16 GDPs and 2 others) never performed RCTs. Therefore, they were categorized ineligible respondents. Accordingly, the overall and non-endodontists (GDPs \& otters) sample sizes were:

$456-18=438$ and $400-18=382$, respectively, resulting in the following response rates:

Overall response rate: $234 / 438=53.4 \%$.

Non-endodontists (GDPs, Endodontic Postgraduate

Programmes students, and others) final response: 202 / 382: $52.9 \%$

Endodontists: $32 / 56=57.1 \%$

This study involves mainly theoretical aspects of endodontics rather than attaining hand skills or mastering new techniques. Dealing with cases of NAPP is well established in the first year of the postgraduate studies programmes in Saudi Arabia. Therefore, participants who were enrolled in Endodontic Postgraduate Studies or Residency programmes, were categorized as endodontists. This also enabled better statistics for some variables.

\section{Participants' experience \& number of cases they perform per week}

Overall, significantly the lowest proportion of respondents $(8.8 \%)$ had more than 20 years' experience $(p<0.001)$ (Table 1). The highest proportion of endodontists $(44.4 \%)$ had 10.1 to 20 years' experience compared to $17.3 \%$ in GDPs group $(p=0.005)$.

There were significant differences between endodontists and GDPs regarding the number of RCTs performed per week $(p<0.001)$ (Table 1). Whilst the highest proportion of GDPs performed 1 to 5 cases (52\%), the highest proportion of endodontists (44.7\%) performed more than 15 cases.

Overall there were no significant differences between endodontists and GDPs $(p=0.176)$ regarding the decision on how to deal with case associated with NPAAA (Table 1). The vast majority of respondents (93.4\%) would treat the tooth $(p<0.001)$ and only $8.8 \%$ of GDPs would either refer to endodontic specialist (7\%) or extract the tooth (1.3\%) $[p<0.001]$.

\section{Management's differences between vital and NPAAA cases \& main Treatment's modalities adopted in NPAAA cases} Overall, the majority (86.3\%) (Endodontists and GDPs) would deal with cases of NPAAA "differently" from that of vital ones $(p<0.001)$ (Table 2$)$.

Table 1 Participants' experience, number of root canal treatments (RCTs) they perform per week and their approach for necrotic pulp associated with acute apical abscess (NPAAA) cases

\begin{tabular}{|c|c|c|c|c|c|c|}
\hline \multirow[t]{2}{*}{ Respondents' Classification } & \multicolumn{6}{|c|}{ Experience of Respondents (Years) } \\
\hline & Up to 2 & 2.1 to 5 & 5.1 to 10 & 10.1 to 20 & More than 20 & Total \\
\hline GDP & $25.5 \%$ & $25.4 \%$ & $25.4 \%$ & $17.3 \%$ & $9.2 \%$ & $100 \%(173)$ \\
\hline Endodontists & $0 \%$ & $21.1 \%$ & $26.3 \%$ & $44.4 \%$ & $7.9 \%$ & $100 \%(38)$ \\
\hline Others & $0 \%$ & $40 \%$ & $20 \%$ & $40 \%$ & $0 \%$ & $100 \%(5)$ \\
\hline Total & $18.1 \%$ & $25 \%$ & $25.5 \%$ & $22.7 \%$ & $8.8 \%$ & $100 \%(216)$ \\
\hline \multirow[t]{2}{*}{ Respondents' Classification } & \multicolumn{6}{|c|}{ Number of RCT cases performed per week } \\
\hline & $1-5$ & $6-10$ & $11-15$ & More than 15 & Total & \\
\hline GDP & $52 \%$ & $28.3 \%$ & $11.6 \%$ & $8.1 \%$ & $100 \%(173)$ & \\
\hline Endodontists & $10.5 \%$ & $26.3 \%$ & $18.4 \%$ & $44.7 \%$ & $100 \%(38)$ & \\
\hline Other & $80 \%$ & $0 \%$ & $20 \%$ & $0 \%$ & $100 \%(5)$ & \\
\hline Total & $45.4 \%(98)$ & $27.3 \%(59)$ & $13 \%(28)$ & $14.4 \%(31)$ & $100 \%(216)$ & \\
\hline \multirow[t]{2}{*}{ Respondents' Classification } & \multicolumn{5}{|c|}{ Management of permanent teeth with NPAAA } & Total \\
\hline & \multicolumn{2}{|c|}{ Treat the tooth } & Extract the tooth & \multicolumn{2}{|c|}{ Refer to an endodontist } & \\
\hline GDP & \multicolumn{2}{|l|}{$91.2 \%$} & $1.8 \%$ & \multicolumn{2}{|l|}{$7 \%$} & $100 \%(173)$ \\
\hline Endodontists & \multicolumn{2}{|l|}{$100 \%$} & $0 \%$ & \multicolumn{2}{|l|}{$0 \%$} & $100 \%(37)$ \\
\hline Other & \multicolumn{2}{|l|}{$100 \%$} & $0 \%$ & \multicolumn{2}{|l|}{$0 \%$} & $100 \%(5)$ \\
\hline Total & \multicolumn{2}{|l|}{$93.6 \%$} & $1.3 \%$ & \multicolumn{2}{|l|}{$5.1 \%$} & $100 \%(215)$ \\
\hline
\end{tabular}


Table 2 Management's differences between vital and NPAAA cases \& main treatment's modalities adopted by Participants in NPAA cases

\begin{tabular}{|c|c|c|c|c|c|c|c|}
\hline \multirow{2}{*}{\multicolumn{2}{|c|}{ Would you deal with NPAA differently }} & \multicolumn{4}{|c|}{ Respondents' Classification } & \multirow{2}{*}{\multicolumn{2}{|c|}{ Total }} \\
\hline & & \multicolumn{2}{|l|}{ GDPs } & Endodontists & Others & & \\
\hline \multicolumn{2}{|l|}{ Using of Rubber Dam } & \multicolumn{2}{|l|}{$13.3 \%$} & $9.7 \%$ & $0 \%$ & \multicolumn{2}{|l|}{$11.9 \%$} \\
\hline \multicolumn{2}{|l|}{ Type of sealer } & \multicolumn{2}{|l|}{$15.6 \%$} & $6.5 \%$ & $20 \%$ & \multicolumn{2}{|l|}{$13.5 \%$} \\
\hline \multicolumn{2}{|l|}{ Size of apical preparation } & \multicolumn{2}{|l|}{$33.3 \%$} & $32.3 \%$ & $60 \%$ & \multicolumn{2}{|l|}{$34.1 \%$} \\
\hline \multicolumn{2}{|l|}{ Type of intra-canal medication } & \multicolumn{2}{|l|}{$78.9 \%$} & $16.1 \%$ & $80 \%$ & \multicolumn{2}{|l|}{$63.5 \%$} \\
\hline \multicolumn{2}{|l|}{ Apical extension of preparation } & \multicolumn{2}{|l|}{$17.8 \%$} & $29 \%$ & $20 \%$ & \multicolumn{2}{|l|}{$20.6 \%$} \\
\hline \multicolumn{2}{|l|}{ Methods for WL measurement } & \multicolumn{2}{|l|}{$6.7 \%$} & $3.2 \%$ & $0 \%$ & \multicolumn{2}{|l|}{$5.6 \%$} \\
\hline \multicolumn{2}{|l|}{ Use of rotary instruments } & \multicolumn{2}{|l|}{$8.9 \%$} & $0 \%$ & $20 \%$ & \multicolumn{2}{|l|}{$7.1 \%$} \\
\hline \multicolumn{2}{|l|}{ Technique of C\&S } & \multicolumn{2}{|l|}{$24.4 \%$} & $22.6 \%$ & $0 \%$ & \multicolumn{2}{|l|}{$23 \%$} \\
\hline \multicolumn{2}{|l|}{ Type of irrigants } & $62.2 \%$ & & $38.7 \%$ & $100 \%$ & $57.9 \%$ & \\
\hline Obturation technique & & $17.8 \%$ & & $3.2 \%$ & $0 \%$ & $13.5 \%$ & \\
\hline Overall Total & & $100 \%(9$ & & $100 \%(31)$ & $100 \%(5)$ & $86.3 \%$ & 126) \\
\hline Respondents' Classification & Instrumentatio & techniqu & & & & Total & \\
\hline & Conventional & Step Ba & & Crown Down & & & \\
\hline GDP & $21.2 \%$ & $45.2 \%$ & & $57.7 \%$ & & $173(10$ & 0\%) \\
\hline Endodontists & $0 \%$ & $8.6 \%$ & & $97.1 \%$ & & $38(100$ & \\
\hline Other & $20 \%$ & $60 \%$ & & $100 \%$ & & $5(100$ & \\
\hline Total & $16 \%$ & $36.8 \%$ & & $68.8 \%$ & & $216(10$ & 0\%) \\
\hline & Irrigants used i & NPAAA & & & & & Total \\
\hline Respondents' Classification & EDTA & NAOCL & $\mathrm{CH}$ & $\mathrm{NAOCL}+(\text { EDTA or } \mathrm{CH})^{\mathrm{a}}$ & $\mathrm{NAOCL}+(\mathrm{EDTA}+\mathrm{CH})^{\mathrm{a}}$ & Other & \\
\hline GDP & $23.1 \%$ & $92.3 \%$ & $17.3 \%$ & $29.5 \%$ & $8.2 \%$ & $3.8 \%$ & $104(100 \%)$ \\
\hline Endodontists & $21.6 \%$ & $100 \%$ & $10.8 \%$ & $21.6 \%$ & $10.8 \%$ & $28 \%$ & 37 (100\%) \\
\hline Other & $40 \%$ & $100 \%$ & $20 \%$ & $40 \%$ & $20 \%$ & $0 \%$ & $5(100 \%)$ \\
\hline Total & $23.3 \%(82.3 \%)$ & $94.5 \%$ & $15.8 \%(100 \%)$ & $27.7 \%$ & $9.1 \%$ & $2.7 \%$ & $141(100 \%)$ \\
\hline Respondents' Classification & Patterns of Ant & biotics Us & & & & & Total \\
\hline & Never & Always & Generally & Frequently & Sometimes & Rarely & \\
\hline GDP & $5.8 \%$ & 21.2 & $26 \%$ & $11.5 \%$ & $24 \%$ & $11.5 \%$ & $100 \%(104)$ \\
\hline Endodontists & $13.5 \%$ & $10.8 \%$ & $10.8 \%$ & $16.2 \%$ & $18.9 \%$ & $29.7 \%$ & $100 \%(37)$ \\
\hline Other & $20 \%$ & $20 \%$ & $0 \%$ & $0 \%$ & $40 \%$ & $20 \%$ & $100 \%(5)$ \\
\hline Total & $8.2 \%$ & $18.5 \%$ & $21.2 \%$ & $12.3 \%$ & $23.3 \%$ & $16.4 \%$ & $100 \%$ (146) \\
\hline
\end{tabular}

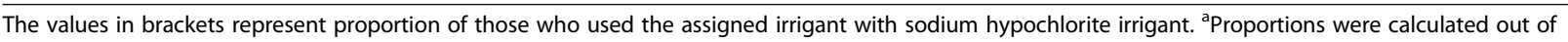
sodium hypochlorite users

\section{Size of apical preparation}

$34.1 \%$ would prepare root canals in cases with NPAAA to different apical sizes from those of vital pulps cases; without significant difference between endodontists and GDPs $(p=0.913)$ (Table 2).

\section{Type of intra-canal medications (ICMs)}

Whist the majority of GDPs (78.9\%) would use different ICMs when dealing with NPAAA cases compared to vital ones, only $16.1 \%$ of endodontists would do so $(p<0.001)$ (Table 2).

\section{Type of sealer}

Only $13.5 \%$ reported the difference in the type of sealer used for RCT with significantly greater proportion of GDPs (15.6\%) compared to that of endodontists $(6.5 \%)[p<0.001]$ (Table 2).

Technique of cleaning \& shaping (C\&S)

$23 \%$ would use different techniques for $C \& S$ of the root canal system in cases of NPAAA. Significantly, Crown Down was the most common technique used for $C \& S$ cases with NPAAA $(68.8 \%)[p<0.001]$; with the vast 
majority of endodontists (97.1\%) using it compared to significantly less GDPs $(57.7 \%)[p<0.001]$ (Table 2).

\section{Type of Irrigants}

Whilst the highest proportion of GDPs (62.2\%) would use different irrigants during instrumentation of cases associated with NPAAA, only $38.7 \%$ would do so $(p=0.023)$ (Table 2). Significantly, the vast majority of respondents $(94.5 \%)$ used sodium hypochlorite irrigant $(p<0.001)$. The proportion of endodontists who used two or three irrigants (40\%) was significantly greater than that of GDPs $(29.5 \%)[p<0.001]$.

\section{Prescribing of antibiotics}

Whilst the highest proportion of endodontists (29.7\%) rarely prescribed antibiotics, only $11.5 \%$ of GDPs did so $(p=0.004)$. By contrast, the highest proportion of GDPs (26\%) generally prescribe antibiotics (Table 2).

\section{First Visit's management of NPAAA cases and its reasons} The most common management of NPAAA cases in the first visit were complete CES of the root canal system and over-instrumentation of the largest root canal $(p<0.001)$. Overall there were significant differences between endodontists and GDPs $(p<0.001)$ (Table 3).

Whilst the highest proportion of GDPs (26.9\%) used to over-instrument the largest canal, the highest proportion of endodontists (56.8\%) used to perform complete C\&S $(p<0.001)$. Also, while $(21.2 \%)$ of GDPs used to partially CES the root canal system to the estimated working length, none of endodontists $(0 \%)$ did so $(p<0.001)$. On the other hand, $21.6 \%$ of endodontists used to perform complete $R C T s$; with only $3.8 \%$ of GDPs were doing so $(p<0.001)$. Overall, significantly the highest proportion (51.7\%) reported their own experience as the reason for their first visit's approaches to NPAAA cases followed by those who did it because they were taught to do so during undergraduate training (37.4\%) [ $p=0.002]$. Forty percent of endodontists reported the postgraduate studies as the reason for doing so. By contrast, the highest proportion of GDPs (56.2\%) reported their own experience as the reason for their first visit's approaches.

\section{First Visit's management of NPAAA cases with non- stopped exudates}

Overall, there was no significant difference between the highest proportion of participants (41.4\%) who used to leave the tooth open (without temporary restoration) and the lower proportion $36.3 \%$ who used to place temporary restoration if there was non-stopped excaudate after the first visit management $(p=0.521)$ (Table 4). However, significantly the lowest proportion (22.6\%) would let the patient wait till the exudates stop or significantly reduce then continue their intended approach [p=0.018]; with

Table 3 First visit's management of NPAAA cases and the reasons participants report

\begin{tabular}{|c|c|c|c|c|}
\hline \multirow{2}{*}{ Management of NPAAA in the first visit } & \multicolumn{3}{|c|}{ Respondents' classification } & \multirow[t]{2}{*}{ Total } \\
\hline & GDPs & Endodontists & Others & \\
\hline Access Cavity & $3.8 \%$ & $5.4 \%$ & $0 \%$ & $4.1 \%$ \\
\hline Over-instrumentation the largest canal & $26.9 \%$ & $8.1 \%$ & $40 \%$ & $22.6 \%$ \\
\hline WL measurement & $1.9 \%$ & $0 \%$ & $0 \%$ & $2 \%$ \\
\hline WL and C\&S of the largest canal & $7.7 \%$ & $0 \%$ & $0 \%$ & $5.5 \%$ \\
\hline Partial C\&S at estimated WL & $21.2 \%$ & $0 \%$ & $20 \%$ & $15.8 \%$ \\
\hline Partial C\&S at Corrected WL & $15.4 \%$ & $8.1 \%$ & $0 \%$ & $13 \%$ \\
\hline Complete C\&S & $19.2 \%$ & $56.8 \%$ & $40 \%$ & $29.5 \%$ \\
\hline Complete RCT & $3.8 \%$ & $21.6 \%$ & $0 \%$ & $8.2 \%$ \\
\hline Overall Total & $100 \%(104)$ & $100 \%(37)$ & $100 \%(5)$ & $100 \%(146)$ \\
\hline \multirow[t]{2}{*}{ Reasons for first visit approach of NPAAA } & \multicolumn{3}{|c|}{ Respondents' classification } & \multirow[t]{2}{*}{ Total } \\
\hline & GDPs & Endodontists & Others & \\
\hline Taught during undergraduate study & $41.9 \%$ & $27 \%$ & $20 \%$ & $37.4 \%$ \\
\hline Lack of time & $12.5 \%$ & $2.7 \%$ & $0 \%$ & $9.6 \%$ \\
\hline Learnt from own experience & $56.2 \%$ & $40.5 \%$ & $40 \%$ & $51.7 \%$ \\
\hline Colleagues' recommendation & $16.5 \%$ & $2.7 \%$ & $20 \%$ & $13.1 \%$ \\
\hline Taught during postgraduation & $0 \%$ & $40 \%$ & $60 \%$ & $12.3 \%$ \\
\hline Taught in a scientific meeting & $1 \%$ & $0 \%$ & $0 \%$ & $0.7 \%$ \\
\hline Dental Literature & $23.1 \%$ & $32.4 \%$ & $40 \%$ & $26 \%$ \\
\hline Total & $100 \%$ & $100 \%$ & $100 \%$ & $100 \%$ \\
\hline
\end{tabular}


Table 4 First visit's management of NPAA cases with non-stopped exudates and the reasons participants report

\begin{tabular}{|c|c|c|c|c|c|}
\hline \multicolumn{2}{|c|}{ First visit management of cases with non-stopped exudates } & \multicolumn{3}{|c|}{ Respondents' classification } & \multirow[t]{2}{*}{ Total } \\
\hline & & GDPs & Endodontists & Others & \\
\hline \multicolumn{2}{|c|}{ Waite till the exudates stop or significantly reduce then continue the intended approach } & $17.3 \%$ & $40.5 \%$ & $0 \%$ & $22.6 \%$ \\
\hline \multirow[t]{3}{*}{ No temporary restoration } & No intra-canal dressing & $3.8 \%$ & $5.4 \%$ & $0 \%$ & $4.1 \% \quad 41.1 \%$ \\
\hline & With dry cotton pellet & $30.8 \%$ & $5.4 \%$ & $20 \%$ & $24 \%$ \\
\hline & Insert intra-canal medication & $11.5 \%$ & $0 \%$ & $0 \%$ & $8.2 \%$ \\
\hline \multirow[t]{2}{*}{ Place temporary restoration } & Insert dry cotton pellet & $7.7 \%$ & $8.1 \%$ & $20 \%$ & $36.3 \%$ \\
\hline & Insert intra-canal medication & $28.8 \%$ & $40.5 \%$ & $60 \%$ & $32.9 \%$ \\
\hline \multicolumn{2}{|l|}{ Total } & $100 \%(104)$ & $100 \%(37)$ & $100 \%(5)$ & $100 \%(146)$ \\
\hline \multirow{2}{*}{\multicolumn{2}{|c|}{ Reasons for This Approach }} & \multicolumn{3}{|c|}{ Respondents' classification } & \multirow[t]{2}{*}{ Total } \\
\hline & & GDPs & Endodontists & Others & \\
\hline \multicolumn{2}{|c|}{ Taught during undergraduate study } & $22.3 \%(95.8)$ & $0 \%(0)$ & $20 \%(4.2)$ & $16.6 \%(100)$ \\
\hline \multicolumn{2}{|l|}{ Lack of time } & $12.6 \%(100)$ & $0 \%(0)$ & $0 \%(0)$ & $9 \%(100)$ \\
\hline \multicolumn{2}{|l|}{ Learnt from own experience } & $48.5 \%(78.1)$ & $35.1 \%(20.3)$ & $20 \%(1.6)$ & $44.1 \%(100)$ \\
\hline \multicolumn{2}{|l|}{ Colleagues' recommendation } & $6.8 \%(100)$ & $0 \%(0)$ & $0 \%(0)$ & $4.8 \%(100)$ \\
\hline \multicolumn{2}{|l|}{ Taught during postgraduation } & $0 \%(0)$ & $43.2 \%(88.9)$ & $40 \%(11.1)$ & $12.4 \%(100)$ \\
\hline \multicolumn{2}{|l|}{ Dental Literature } & $9.7 \%(52.6)$ & $21.6 \%(42.1)$ & $20(5.3)$ & $13.1 \%(100)$ \\
\hline \multicolumn{2}{|l|}{ Total } & $100 \%$ & $100 \%$ & $100 \%$ & $100 \%$ \\
\hline
\end{tabular}

significantly more endodontists $(40.5 \%)$ than GDPs $(17.3 \%)$ [ $p=0.002]$. By contrast, the highest proportion of GDPs (30.8\%) would insert only dry cotton pellet without temporizing the tooth till next visit. In addition, the proportion of endodontists who would insert ICMs and temporize the tooth (40.5\%) was significantly greater than that of GDPs who would do the same (28.8\%) [ $p=0.002]$. The proportion of endodontists who would temporize the tooth in the first visit (81.8\%) was significantly greater than that of GDPs (44.2\%).

While the most common reason for endodontists' approaches (43.2\%) was postgraduate studies' learning, the most common reason for GDPs was learning from their own experience $(p<0.001)$ (Table 4$)$.

\section{Management of NPAAA cases with little exudates after complete $\mathrm{C} \& S$ and its reasons}

The majority of respondents $(80.8 \%)$ used to insert temporary restoration, with $(69.2 \%)$ or without intracanal medications (11.6\%), if there had been little exudates after the first visit management (Table 5). The second most common management $(12.6 \%)$ was to let the patient wait till the exudates stop or significantly reduce then continue their intended. Overall, there were significant differences between GDPs and endodontists $(p<0.010)$. Whilst the second common approach by endodontists (29.7\%) was let the patient wait till the exudates stop or significantly reduce then continue their intended, insert dry cotton pellet only without temporizing the tooth till next visit was the second most common management adopted by GDPs
(15.4\%). However, there was no significant difference between the proportion of endodontists who used to insert temporary restoration with intracanal medications (62.2\%) and those of GDPs who were doing (70.2\%) [ $p<0.097]$.

Overall, there were significant differences between endodontists and GDPs in reporting the reasons for their management of little exudate after CES ( $p>0.05)$. The first and second most common reasons for GDPs were that they were taught to do so during undergraduate study and their own experience (52 and 46.1\%, respectively). However, the most common reason for endodontists was that they were taught to do so during postgraduate studies (61.1\%).

\section{Comparison between Management of First Visit Significant Exudates and Little Exudates after C\&S}

Of those who would wait till the significant exudate stops then continue treatment in the first visit, a significantly high proportion $(54.5 \%, p=0.020)$ would temporize the tooth till next visit if little exudates still present after CES of the root canal system in the first visit (Table 6). Of those who would leave the tooth open if non-stopped exudates presents in the first visit, the majority (81.9\%) would temporize the tooth if little exudates present after $C \& S(p<0.001)$. Of those who used to temporize the tooth after the first visit associated with nonstopped exudates, 5\% would wait till exudate stop then continue treatment in case of little exudates presented in the first visit. 
Table 5 Management of NPAA cases with little exudates after complete cleaning and shaping (C\&S) of the root canal system and the reasons participants report

\begin{tabular}{|c|c|c|c|c|c|}
\hline \multirow[t]{2}{*}{ First visit management of little exudates after complete C\&S } & \multicolumn{3}{|c|}{ Respondents' classification } & \multicolumn{2}{|l|}{ Total } \\
\hline & GDPs & Endodontists & Others & & \\
\hline Waite till the exudates stop or significantly reduce then continue your intended approach & $6.7 \%$ & $29.7 \%$ & $0 \%$ & $12.3 \%$ & (18) \\
\hline Leave tooth open without neither dressing nor temporization till next visit & $1.9 \%$ & $0 \%$ & $0 \%$ & $1.4 \%$ & $6.8 \%(10)$ \\
\hline Insert dry cotton pellet only without temporization till next visit & $1.9 \%$ & $5.4 \%$ & $0 \%$ & $2.7 \%$ & \\
\hline Insert intra-canal medication without temporization till next visit & $3.8 \%$ & $0 \%$ & $0 \%$ & $2.7 \%$ & \\
\hline Insert dry cotton pellet only and temporization till next visit & $15.4 \%$ & $2.7 \%$ & $0 \%$ & $11.6 \%$ & $80.8 \%(118)$ \\
\hline Insert intra-canal medication and temporization till next visit & $70.2 \%$ & $62.2 \%$ & $100 \%$ & $69.2 \%$ & \\
\hline Total & $100 \%(104)$ & $100 \%(37)$ & $100 \%(5)$ & $100 \%($ & 146) \\
\hline
\end{tabular}

\section{Discussion}

There has been need to explore the real-life practice of GDPs and endodontists when dealing with cases of NPAAA and to identify the reasons behind their approaches. Generally, more endodontists had more than ten years' experience than GDPs than GDPs. This might be explained by the fact that endodontists have to spend three to five years acquiring endodontic postgraduate training. As expected, there were significant differences between endodontists and GDPs regarding the number of RCTs performed per week; whilst most GDPs performed up to five cases per week, the highest proportion of endodontists performed more than 15 cases. While the full time of endodontists is devoted for endodontic treatment, GDPs usually perform other types of dental treatments. Another possible reason is that GDPs may refer complex cases or retreatment cases to endodontist [5]. The definition of complex cases from GDPs' prospective should be established; because the vast majority of GDPs in the current study used to treat cases with NPAAA. It could be assumed that complex or difficult cases, from GDPs' point of view, imply those cases with complex root canal anatomy or defective old root canal fillings. Nevertheless, these findings reflect participants' intention to preserve teeth involved in NPAAA. This is especially true with the fact that $6.1 \%$ would refer the cases to endodontists and only (1.8\%) would extract teeth involved with such cases. In addition, few years ago more GDPs in Saudi dental practice (5\%) used to extract such cases [5]. However, dealing with NPAAA cases may be challenging and possess some difficulties. Accordingly, clinicians may deal with them differently when compared with vital-pulp cases. The majority of the current study's respondents would do so. In the following we will try to discuss some of these different aspects, if any.

Almost $12 \%$ of respondents would use rubber dam (RD) isolation when dealing with NPAAA cases. This may explain the perception of these respondents towards the different pathological condition of NPAAA cases compared to vital-pulp cases. Different types of bacteria are associated or involved with different pathological endodontic conditions [6], hence these respondents were careful to prevent or reduce additional microbial invasion to the root canal system. RD isolation may also better control pus drainage. Nevertheless, it is well documented that RD is not commonly used by GDPs in many countries [7-10]. A recent study showed that only $21.6 \%$ of GDPs were using RD in Saudi Arabia [11]. While it is common, though disappointedly, for GDPs not to use RD, it is unaccepted that $9.7 \%$ of endodontists to use RD in NPAAA cases rather than vital-pulp cases. With the fact that RD isolation in endodontics is a standard of care [12].

Only $13.5 \%$ of participants (GDPs and endodontists) used to use different sealers when dealing with NPAAA

Table 6 Comparison between management of first visit significant exudates and little exudates after C\&S

\begin{tabular}{|c|c|c|c|c|}
\hline \multirow{2}{*}{$\begin{array}{l}\text { Management of First Visit Non-stopped } \\
\text { Exudates }\end{array}$} & \multicolumn{3}{|c|}{ Management of First Visit Little Exudates after C\&S } & \multirow[t]{2}{*}{ Total } \\
\hline & $\begin{array}{l}\text { Wait till exudate stop then continue } \\
\text { treatment }\end{array}$ & $\begin{array}{l}\text { Leave tooth open till next } \\
\text { visit }\end{array}$ & $\begin{array}{l}\text { Temporize the tooth till next } \\
\text { visit }\end{array}$ & \\
\hline $\begin{array}{l}\text { Wait till exudate stop then continue } \\
\text { treatment }\end{array}$ & $45.5 \%$ & $0 \%$ & $54.5 \%$ & $\begin{array}{l}100 \% \\
(33)\end{array}$ \\
\hline $\begin{array}{l}\text { Leave tooth without temporization till } \\
\text { next visit }\end{array}$ & $0 \%$ & $18.9 \%$ & $81.9 \%$ & $\begin{array}{l}100 \% \\
(53)\end{array}$ \\
\hline Temporize the tooth till next visit & $5 \%$ & $0 \%$ & $95 \%$ & $\begin{array}{l}100 \% \\
(60)\end{array}$ \\
\hline Total & $12.3 \%$ & $6.8 \%$ & $80.8 \%$ & $\begin{array}{l}100 \% \\
(146)\end{array}$ \\
\hline
\end{tabular}


cases. One assumption for such practice is that this group of clinicians' demand better antimicrobial effects. The antimicrobial effects of zinc oxide \& eugenol-based sealers is well established [13]. It has been thought that calcium hydroxide-based sealers would have better biological and antibacterial properties which could contribute to better perapical tissues healing and repair. However, clinical and experimental studies have not shown such superiority $[14,15]$. The MTA-based sealer has been recently introduced and has shown promising results [16]. Nevertheless, drawing conclusions on the impact of different sealers on treatments' long-term outcome should be based on clinical studies with sufficient follow-up periods. In addition, the current study did not ask the participants about the type of sealer they used in cases of NPAAA. This could be one limitation that necessitates further investigation.

There is a general belief that necrotic pulp cases, especially those associated with apical pathosis should be prepared to a larger apical size than vital-pulp cases. A previous clinical study found that enlarging the apical portion of root canals three sizes larger than the first file that bound at working length was sufficient [17]. Some authors have suggested creating a 'larger' apical preparation followed by a one-week dressing of calcium hydroxide [18-20]. Other authors have suggested enlarging the canal terminus to a pre-determined size beyond 35 or 40 [20-27]. However, it was suggested that larger tapers is more important than the final apical size; because a small taper size of 0.10 allowed minimum instrumentation of the apical part of the root canal systems [28]. One systematic review showed that canal enlargement reduces bioburden within the root canal system [29]. It revealed that in cases with necrotic pulps and periapical lesions, enlargement of the apical size would result in an increased healing outcome (clinically and radio-graphically) [29]. A very recent study revealed significant bacterial reduction when root canals of teeth involved with apical periodontitis were prepared to an S3 TFA file compared to S2 and S1 files [30]. The current study revealed that one third of participants were following this trend and they would prepare the root canals of NPAAA cases to different sizes of that in vital-pulp cases. Nevertheless, the influence of different apical enlargement on the treatment long-term outcome, especially in NPAAA cases, should be established systematically. This need was reflected on the current study; because two third of participants would not prepare the NPAAA cases to different apical size of that in vitalpulp cases. It is important to indicate that some studies proposed and investigated the interaction between the apical size preparation and other factors such as irrigation and obturation).

In addition to the antimicrobial and tissues- dissolving effects, irrigants are essentially used to remove and wash the debris out of the root canal system. Due to the extensive microbial invasion in NPAAA cases compared to those of vital-pulp ones, different irrigation protocols and stronger irrigants may be used [31]. Unlike endodontists, most GDPs in the current study used different irrigants when dealing with NPAAA cases. This again may reflect their perception to the pathological condition of the pulpal and periapical tissues in NPAAA cases when compared to vital-pulp cases. If this is the case, GDPs need to not underestimate the desired antimicrobial effects of irrigants in vital-pup cases as well. By contrast, the lowest proportion of endodontists used different irrigants. Endodontists are usually aware of the important of irrigation in elimination intracanal infection regardless of the pathological condition. There have been many solutions used as irrigants in endodontics; including sodium hypochlorite $(\mathrm{NaOCl})$, chlorohexidine (CHX) and Ethylene diamine tetra acetic acid (EDTA). $\mathrm{NaOCl}$ has been the most commonly used irrigants [32]. The current study is not an exception and showed that the vast majority of clinicians were using it in NPAAA cases. It is an excellent antibacterial agent, capable of dissolving necrotic and vital tissues and the organic components of dentin and biofilms. Hence it has been the standard irrigant with which other and new irrigants are compared [33]. Chlorohexidine has been also known for its good antimicrobial effects, especially as adjunctive irrigant [34]. However, one limitation of both irrigants, is that their inferior ability in removing intracanal smear layer. Hence EDTA is strongly recommended for such a purpose [31]. An irrigation protocol that ensures elimination of microbs, dissolving pulp tissues and removing smear layer by combined use of selective irrigants in different sequences, is paramount. It is well established that such a protocol is key factor in better cleaning of the root canal system and contributes to better long-term treatment outcome [34]. Within this respect, the current study revealed the need to raise the awareness of GDPs for implementing multi-irrigants protocol as only one third of them use more than one irrigant.

The most common different practice of GDPs towards NPAAA cases from that in vital-pulp ones was using different type of ICMs; with only $16.1 \%$ of endodontists were doing so. This again, almost reflect GDPs perception of the significant microbial invasion and the essential need to eliminate intracranial infection. Also, it may mirror GDPs' understanding of using different ICMs according to different pulpal and periapical pathological conditions and the associated symptoms. Nevertheless, the current results are consistent with those obtained in a very recent study conducted in Saudi Arabia which showed general trend among GDPs to use different ICMs according to different pulpal and periapical diseases [35]. These findings validate the current study and confirm that it was conducted systematically. The previous study revealed that $\mathrm{CH}$ was the most common ICM used by Saudi dental clinicians; 
GDPs and endodontists [35]. A previous study in the United States, also, found that $\mathrm{CH}$ was the most frequently used ICM all necrotic pulps cases [36]. The antimicrobial properties of $\mathrm{CH}$ dressing has been controversial [37], though it has been recommended for use in teeth with necrotic pulp tissue and bacterial contamination [2] because of its effectiveness in inhibiting microbial growth [38]. It probably has little benefit with vital pulps [2].

With NPAAA cases, extra caution and care should be exercised so the necrotic debris are not pushed apically, hence beyond the apex, during $C \& S$ to reduce posttreatment discomfort or pain. Crown-down instrumentation technique has been known as the least technique causing debris extrusion beyond the apex [39]. In addition, it enables removing the intracanal infection sequentially from the coronal portion down to the apical portion of the root canal system. The proportion of respondents, in the current study, who used this technique in cases with NPAAA was significantly greater than those who used Step-Back or Conventional ones. Unsurprisingly, the vast majority of endodontists used Crown-Down technique compared to lower proportion of GDPs. This indicates that GDPs need to update their knowledge and implement Crown-Down more as a technique of choice when dealing with NPAAA cases.

The results showed a clear trend among GDPs towards prescribing antibiotics when dealing with NPAAA cases. Whilst the highest proportion of endodontists (29.7\%) rarely prescribed antibiotics, the highest proportion of GDPs (26\%) generally prescribe. These findings are consistent with those obtained in a very recent systematic review [40]. However, the current results should be carefully interpreted because the current survey did not differentiate between presence and absence of swelling. This can be one limitation of the study which suggests further research to explore clinicians' preferences on prescribing antibiotics for different endodontic diseases as well as to explore the most common antibiotics used in individual diseases. Systemic antibiotics are better prescribed for the diffuse, rapidly spreading or persistent infections with systemic signs and symptoms such as cellulitis or persistent swelling. The antibiotic therapy in such cases, is an adjunct to debridement of the root canal system [2]. A recent systematic review concluded that the use of systemic antibiotics is not necessary and not recommended if the the infection is localized [3]. Improper use of antibiotics is one main factor that contributes to the emerging oral bacteria resistance to commonly used antibiotics [41]. Improper use of antibiotics includes: use in cases with no infection, erroneous choice of the agent, dosage or duration of therapy, and excessive use in prophylaxis [42]. Nevertheless, the results indicate that clinicians, especially GDPs, should exercise additional care when prescribing antibiotics.
Management of NPAAA cases has been controversial, especially in terms of leaving the tooth open. Unfortunately, there is little evidence and reports on the best management and treatment modalities. An old survey in the United States revealed that most endodontists would do complete canal debridement shorter than the working length (WL) in cases no swelling present $[43,44]$. By contrast, they would over-instrument the canals and leave the tooth open if there is swelling $[43,44]$. Leaving the tooth open is no longer accepted nowadays and is rarely considered in very limited cases, especially for endodontists. A recent study in the United States revealed that most Endodontic Diplomats would do complete $C \& S$ regardless of the swelling; with up to $38 \%$ who left the tooth open in case of swelling [36]. It is well accepted among endodontists that full debridement of the root canal system, if time permits, in the first visit, is the preferred therapeutic procedure of NPAAA cases [2]. However, drainage should be considered if time is limited and does not allow complete C\&S [2]. As expected, endodontists in the current study showed awareness of such good practice as most of them would $C \& S$ root canals to the full working length. By contrast, a lower proportion of GDPs would do so; with the highest proportion of them would over-instrument the largest canal only. Lack of time could be one main reason for this policy. Another possibility is that GDPs aim only at reducing the pressure and relief patients' emergency situation. Interestingly, $21.6 \%$ of endodontists would perform complete RCT. The long-term treatment outcome and post-operative pain are the crucial debate in this respect. Reports indicated that there may be no difference in post-treatment pain if root canals are filled at the time of the emergency versus a later date [45] (Eleazer and Eleazer 1998). However, the long-term prognosis of such treatment is questionable $[46,47]$. Nevertheless, a previous study showed no difference in treatment outcome between single-visit and two-visit treatments [48]. Overall, most clinician of the current study, especially GDPs, reported their own experience as the reason for their approaches to NPAAA cases in the first visit. This reflects the lack of scientific evidence that clinicians can rely on when dealing with such cases. This is especially true as most endodontist were equally relying on either their own experience or on what they were taught during postgraduate endodontic programmes.

Decision on NPAAA cases with significant exudates after first visit's procedures is one of the most crucial decision-making skills, especially with the lack of strong scientific evidence [49]. This reflected clearly on GDPs options as the highest proportion reported their own experience as the main reason for their decision. This was confirmed, somehow, by endodontists group as it was the second most common reason. The highest proportion of GDPs (30.8\%) would insert dry cotton pellet only without temporizing the tooth till next visit. Moreover, the 
trend within the GDPs group was to leave the tooth open till next visit. These findings are consistent with those obtained in a previous study which revealed that leaving the tooth open for drainage is still present in the United Kingdom's dental practice [4]. With only $12 \%$ of GDPs, in the current study, reporting lack of time as a reason for their decision, it is clearly that they need to understanding that leaving the tooth open till next visit is inappropriate because it allows more microbial invasion to the root canal system and may cause more complications $[49,50]$. Foreign objects may enter the root canal system or even to the periapical area [51]. With very little scientific evidence [49], the best action a clinician may take in case of significant exudates is that he/she steps away from the patient, or ask the patient to wait in the waiting area, for some time to allow the drainage to continue and hopefully resolve on the same treatment visit [2]. As expected, endodontic showed, to some extent, good practice as one of the highest proportions of them opted this good approach. Nevertheless, the trend of leaving the tooth open dramatically reduced in cases of little exudates after $C \& S$. Of those who would leave the tooth open if non-stopped exudates presents in the first visit, the majority (81.9\%) would temporize the tooth if little exudates present after C\&S. It is clearly that the presence of the exudates impairs clinicians from taking the right decision. Clinicians need to understand that even with the presence of exudates, giving the tooth enough time in the first visit then $C \& S$ is usually the practice of choice that results in good drainage. More importantly, they need to improve their practice and do their best not to leave the tooth open regardless the tooth initial conditions.

Nevertheless, this study was conducted in Saudi dental practice, which can be considered as one limitation. Further studies in other countries with different dental practices environment, regulations and set-ups are paramount to conclude general recommendations.

\section{Conclusions}

Within the limitations of the current study, the following can be concluded:

- Clinicians showed clear trend towards preserving teeth involved in NPAAA, though they, especially GDPs, opted to treat them differently from those with vital-pulp cases. The main differences were using different ICMs and different irrigants, C\&S to different apical size preparation.

- GDPs need to improve their practicing in specific aspects when dealing with NPAAA cases such as implementing Crown-Down technique and multiirrigants protocol while $C \& S$, limit prescribing antibiotics, perform complete debridement of the root canal system and not to leave the tooth open between visits.

- Though endodontists showed overall good practice, they need to completely adhere to the obligatory use of rubber dam.

- There is urgent need for clear guidelines that are based on scientific evidence because clinicians, especially GDPs, relied on their own experiences in managing NPAA cases.

\section{Additional file}

Additional file 1: The survey form of Preferences of Dentists and endodontists, on Management of Necrotic Pulp with Acute Apical Abscess. (DOCX $39 \mathrm{~kb}$ )

\section{Abbreviations}

C\&S: cleaning and shaping; $\mathrm{CH}$ : calcium hydroxide; $\mathrm{CHX}$ : chlorohexidine; EDTA: ethylene diamine tetra acetic acid; GDPs: general dental practitioners; NPAAA: necrotic pulp with acute apical abscess

\section{Acknowledgements}

The author would like to thanks all participants who responded to this survey study.

\section{Availability of data and materials}

The datasets used and/or analysed during the current study are available from the corresponding author on reasonable request.

\section{Authors' contributions}

This study has been conduct by a single author (AAM) who is submitting for publication consideration. The author read and approved the final manuscript.

Ethics approval and consent to participate

The study was approved by a registered ethical committee (The Research \& Ethics Committee at Taibah University). The participants consent was waived by the ethical committee.

Competing interests

The author declares that he has no competing interests.

\section{Publisher's Note}

Springer Nature remains neutral with regard to jurisdictional claims in published maps and institutional affiliations.

Received: 26 September 2017 Accepted: 1 June 2018

Published online: 19 June 2018

References

1. Kakehashi S, Stanley HR, Fitzgerald RJ. The effects of surgical exposures of dental pulps in germfree and conventional laboratory rats. J South Calif Dent Assoc. 1966;34:449-51.

2. Torabinejad M, Walton R. Endodontics: principles and practice. 4th ed. St. Louis: Saunders; 2009

3. Aminoshariae A, Kulild JC. Evidence-based recommendations for antibiotic usage to treat endodontic infections and pain: A systematic review of randomized controlled trials. J Am Dent Assoc. 2016;147:186-91.

4. Eliyas S, Barber MW, Harris I. Do general dental practitioners leave teeth on 'open drainage'? Br Dent J. 2013;215:611-6.

5. Al-Fouzan KS. A survey of root canal treatment of molar teeth by general dental practitioners in private practice in Saudi Arabia. Saudi Dent J. 2010; 22:113-7.

6. Siqueira JF Jr, Rocas IN. Diversity of endodontic microbiota revisited. J Dent Res. 2009;88:969-81.

7. Going RE, Sawinski VJ. Parameters related to the use of the rubber dam. J Am Dent Assoc. 1968;77:598-601. 
8. Joynt RB, Davis EL, Schreier PH. Rubber dam usage among practicing dentists. Oper Dent. 1989;14:176-81.

9. Marshall K, Page J. The use of rubber dam in the UK. A survey. Br Dent J. 1990;169:286-91.

10. Whitworth JM, Seccombe GV, Shoker K, Steele JG. Use of rubber dam and irrigant selection in UK general dental practice. Int Endod J. 2000;33:435-41.

11. Madarati AA. Why dentists don't use rubber dam during endodontics and how to promote its usage? BMC Oral Health. 2016;25(16):24.

12. European Endodontic Society. Quality guidelines for endodontic treatment: consensus report of the European Society of Endodontology. Int Endod J. 2006;39:921-30

13. Mickel AK, Nguyen TH, Chogle S. Antimicrobial activity of endodontic sealers on Enterococus faecalis. J Endod. 2003;29:257-8.

14. Desai S, Chandler N. Calcium hydroxide-based root canal sealers: a review. J Endod. 2009;35:475-80.

15. Mohammadi Z, Dummer PM. Properties and applications of calcium hydroxide in endodontics and dental traumatology. Int Endod J. 2011;44: 697-730.

16. Mestieri LB, Gomes-Cornelio AL, Rodrigues EM, Salles LP, Bosso-Martelo R, Guerreiro-Tanomaru JM, Tanomaru-Filho M. Biocompatibility and bioactivity of calcium silicate-based endodontic sealers in human dental pulp cells. J Appl Oral Sci. 2015;23:467-71.

17. Saini HR, Tewari S, Sangwan P, Duhan J, Gupta A. Effect of different apical preparation sizes on outcome of primary endodontic treatment: a randomized controlled trial. J Endod. 2012;38:1309-15.

18. Orstavik D, Kerekes K, Molven O. Effects of extensive apical reaming and calcium hydroxide dressing on bacterial infection during treatment of apical periodontitis: a pilot study. Int Endod J. 1991;24:1-7.

19. McGurkin-Smith R, Trope M, Caplan D, Sigurdsson A. Reduction of intracanal bacteria using GT rotary instrumentation, 5.25\% NaOCl, EDTA, and $\mathrm{ca}(\mathrm{OH}) 2$. J Endod. 2005;31:359-63.

20. JFJr S, Rocas IN, Riche FN, Provenzano JC. Clinical outcome of the endodontic treatment of teeth with apical periodontitis using an antimicrobial protocol. Oral Surg Oral Med Oral Pathol Oral Radiol Endod. 2008;106:757-62.

21. Ram Z. Effectiveness of root canal irrigation. Oral Surg Oral Med Oral Pathol. 1977;44:306-12.

22. Salzgeber RM, Brilliant JD. An in vivo evaluation of the penetration of an irrigating solution in root canals. J Endod. 1977;3:394-8.

23. Chow TW. Mechanical effectiveness of root canal irrigation. J Endod. 1983;9: 475-9.

24. Card SJ, Sigurdsson A, Orstavik D, Trope M. The effectiveness of increased apical enlargement in reducing intracanal bacteria. J Endod. 2002;28:779-83.

25. Rollison S, Barnett F, Stevens RH. Efficacy of bacterial removal from instrumented root canals in vitro related to instrumentation technique and size. Oral Surg Oral Med Oral Pathol Oral Radiol Endod. 2002;94:366-71.

26. Usman N, Baumgartner JC, Marshall JG. Influence of instrument size on root canal debridement. J Endod. 2004;30:110-2.

27. Bierenkrant DE, Parashos $\mathrm{P}$, Messer $\mathrm{HH}$. The technical quality of nonsurgical root canal treatment performed by a selected cohort of Australian endodontists. Int Endod J. 2008:41:561-70.

28. Albrecht LJ, Baumgartner JC, Marshall JG. Evaluation of apical debris removal using various sizes and tapers of ProFile GT files. J Endod. 2004 Jun; 30(6):425-8

29. Aminoshariae A, Kulild J. Master apical file size - smaller or larger: a systematic review of microbial reduction. Int Endod J. 2015;48:1007-22.

30. Rodrigues RCV, Zandi H, Kristoffersen AK, Enersen M, Mdala I, Ørstavik D, Rôças IN, Siqueira JF Jr. Influence of the apical preparation size and the Irrigant type on bacterial reduction in root canal-treated teeth with apical periodontitis. J Endod. 2017;43:1058-63.

31. Johnson W, Kulid JC, Tay F. Obturation of the cleaned and shaped root canal system. Chapter 7. In: Hargreaves KM, Berman LH, editors. Cohens' pathways of the pulp. 11th ed. St. Louis, Missouri: Elsevier Inc; 2016.

32. Willershausen I, Wolf TG, Schmidtmann I, Berger C, Ehlers V, Willershausen B, Briseño B. Survey of root canal irrigating solutions used in dental practices within Germany. Int Endod J. 2015:48:654-60.

33. Jose J, Krishnamma S, Peedikayil F, Aman S, Tomy N, Mariodan JP. Comparative Evaluation of Antimicrobial Activity of QMiX, 2.5\% Sodium Hypochlorite, 2\% Chlorhexidine, Guava Leaf Extract and Aloevera Extract Against Enterococcus faecalis and Candida albicans - An in-vitro Study. J Clin Diagn Res. 2016;10(5):ZC20-3.
34. Ng YL, Mann V, Gulabivala K. A prospective study of the factors affecting outcomes of nonsurgical root canal treatment: part 1: periapical health. Int Endod J. 2011:44:583-609.

35. Madarati AA, Zafar MS, Sammani AMN, Mandorah AO, Bani-Younes HA. Preference and usage of intracanal medications during endodontic treatment. Saudi Med J. 2017;38:755-63.

36. Lee MJ, Stewart WGHJ, Caine R. Current trends in endodontic practice: emergency treatments and technological armamentarium. J Endod. 2009;35:35-9.

37. Balto KA. Calcium hydroxide has limited effectiveness in eliminating bacteria from human root canal. Evid Based Dent. 2007;8:15-6.

38. Law A, Messer $\mathrm{HH}$. An evidence-based analysis of the antibacterial effectiveness of intracanal medicaments. J Endod. 2004;30:689-94.

39. Sowmya HK, Subhash TS, Goel BR, Nandini TN, Bhandi BSH. Quantitative assessment of apical debris extrusion and intracanal debris in the apical third, using hand instrumentation and three rotary instrumentation systems. J Clin Diagn Res. 2014;8:206-10.

40. Segura-Egea JJ, Martín-González J, Jiménez-Sánchez MDC, Crespo-Gallardo I, Saúco-Márquez JJ, Velasco-Ortega E. Worldwide pattern of antibiotic prescription in endodontic infections. Int Dent J 2017; 67: 197-205.

41. Kuriyama T, Williams DW, Yanagisawa M, Iwahara K, Shimizu C, Nakagawa K, Yamamoto E, Karasawa T. Antimicrobial susceptibility of 800 anaerobic isolates from patients with dentoalveolar infection to 13 oral antibiotics Oral Microbiol Immunol. 2007;22:285-8.

42. Pallasch TJ. Pharmacokinetic principles of antimicrobial therapy. Periodontol 2000. 1996;10:5-11.

43. Dorn SO, Moodnik RM, Feldman MJ, Borden BG. Treatment of the endodontic emergency: a report based on a questionnaire-part I. J Endod. 1977;3:94-100.

44. Dorn SO, Moodnik RM, Feldman MJ, Borden BG. Treatment of the endodontic emergency: a report based on a questionnaire-part II. J Endod. 1977;3:153-6.

45. Eleazer PD, Eleazer KR. Flare-up rate in pulpally necrotic molars in one-visit versus two-visit endodontic treatment. J Endod. 1998:24:614-6.

46. Sjogren U, Figdor D, Persson S, Sundqvist G. Influence of infection at the time of root filling on the outcome of endodontic treatment of teeth with apical periodontitis. Int Endod J. 1997;30:297-306.

47. Trope ME, Delano EO, Orstavik D. Endodontic treatment of teeth with apical periodontitis: single vs. multivisit treatment. J Endod. 1999;25:345-50.

48. Penesis VA, Fitzgerald PI, Fayad MI, Wenckus CS, BeGole EA, Johnson BR. Outcome of one-visit and two-visit endodontic treatment of necrotic teeth with apical periodontitis: a randomized controlled trial with one-year evaluation. J Endod. 2008:34:251-7.

49. Bence R, Meyers RD, Knoff RV. Evaluation of 5,000 endodontic treatments: incidence of the opened tooth. Oral Surg Oral Med Oral Pathol. 1980:49:82-4.

50. Wein F. Closing a tooth left open for drainage. Chronicle. 1975;38:406-7. 410

51. Simon JH, Chimenti RA, Mintz GA. Clinical significance of the pulse granuloma. J Endod. 1982;8:116-9.

\section{Ready to submit your research? Choose BMC and benefit from:}

- fast, convenient online submission

- thorough peer review by experienced researchers in your field

- rapid publication on acceptance

- support for research data, including large and complex data types

- gold Open Access which fosters wider collaboration and increased citations

- maximum visibility for your research: over $100 \mathrm{M}$ website views per year

At BMC, research is always in progress.

Learn more biomedcentral.com/submissions 